\section{ARCHITECTURAL PRINCIPLES IN ARTHRODESIS}

By H. A. Brittain, O.B.E., M.A., M.Ch., F.R.C.S. and Edition. Pp. xi + r 96, with 257 illustrations, 9 in full colour. Edinburgh: E. \& S. Livingstone, Ltd. I952. $42 \mathrm{~s}$.

This is the second edition of a monograph that is already well known to orthopaedic surgeons. The author's most important contribution is undoubtedly his method of ischio-femoral arthrodesis, which has stood the test of time and proved its value, especially in the treatment of tuberculous arthritis of the hip. The technique of this operation, slightly modified since the first edition, is fully described and well illustrated. In this edition there also appears, for the first time, a detailed account of a new method of ischio-femoral fusion-the Varthrodesis-which is giving promising results in non-destructive lesions of the hip joint, especially osteoarthritis. The method combines rigid fixation of the joint, by a long nail driven across it, with insertion of a stout bone graft through a wide-bore drill hole in the femur into the ischium; osteotomy is avoided and early weight-bearing is permitted, seemingly without prejudicing the chances of fusion. The results of these two methods of arthrodesis of the hip suggest that Mr. Brittain's main 'architectural principle'-that a bone graft in compression is more likely to succeed than one in tension-is sound.

The section devoted to arthrodesis of the shoulder is a further notable contribution. Again the technique is such that a stout bone graft bridging the joint is under compression stress, the graft in this case being placed between the upper part of the shaft of the humerus and the axillary border of the scapula. Similar principles have been applied in the fusion of other joints, but on the whole the case for them is less convincing than it is in the hip and shoulder.

A number of criticisms must be made; the style is in places loose and the use of anatomical nomenclature inconsistent. Mistakes in the text and legends suggest a somewhat perfunctory reading of the proofs. No doubt the profusion of illustrations and the use of colour blocks are responsible for high costs. By suitable economies the book could perhaps have been produced at a price more consistent with its 70 pages of text, without detriment to its practical value. The younger surgeon, to whom it is chiefly of interest, would then have been more tempted to purchase it rather than to borrow it from the library.

\section{LAW RELATING TO HOSPITALS AND KINDRED INSTITUTIONS}

\section{Supplement to 1949 (Second) Edition}

By S. R. Speller, LL.B. Pp. viii +87 . London: H. K. Lewis \& Co., Ltd. I95I. I2s. 6d.

This little book sets out the additions to and changes in the law relating to hospitals caused by acts of Parliament, statutory rules and orders, decisions of the Courts and circulars from the Ministry between 1949 and 1951 . It professes to be only a supplement, not an independent work, $\because$ and the new material is arranged under references $\overline{\bar{s}}$ to the pages of the main book. The supplement, $\vec{\sigma}$ dealing with some important developments in the lav relating to hospitals, is a most useful addition $\frac{\overline{\bar{N}}}{\bar{N}}$ to the main book, which should not now be used without it.

\section{CIBA FOUNDATION COLLOQUIA ON ENDOCRINOLOGY}

\section{Volume II. Steroid Metabolism and Estimation}

General Editor for the Ciba Foundation, G. E. W.

Wolstenholme, O.B.E., M.A., M.B., B.Ch., assisted by MARGARET P. CAMERON, M.A., $\infty$ A.B.L.S. Pp. xix +429 , with 96 illustrations. London: J. \& A. Churchill, Ltd. 1952. 35s. O

This book is written for the steroid biochemist $A$ and the clinical endocrinologist and both will find the more recent methods and investigations des-? cribed in detail and well documented. The dis- 5 cussion of experts unfolds the complex pattern of $-\overrightarrow{ }$ steroid metabolism. This is of real practical interest to the clinician who uses ACTH and the $\underset{\mathbb{D}}{\mathbb{D}}$ consultant who directs the investigation of endo 3 crine cases; though it must be realized that the reader is left to draw his own conclusions. In th connection it is perhaps a little unfortunate that $\vec{\varphi}$ some authors appear to be over-enthusiastic in the clinical value they attach to their results, part ticularly in respect of pregnancy diagnosis. The methods of assay are mostly discussed by the authors themselves, and as is only possible in the $\bar{\partial}$ verbatim report of a tête-à-tête meeting all the interesting 'side-shows' of the methods are $\mathbb{Q}$ brought to light.

In criticism of the book, one would have liked to see some of the formulae better drawn, but on the whole the production is free from errors. The wealth of material and the reasonable price make it an attractive proposition.

E.K.

\section{MODERN PRACTICE IN TUBERCULOSIS}

\section{Vols. I and II}

Edited by T. Holmes Sellors, M.A., D.M., 웅 M.Ch., F.R.C.S., and J. L. LivingstonE, M.D., J F.R.C.P. Pp. xxxiv + 942, with 266 illustrations, 3 in colour. London: Butterworth \& Co. 1952. $£ 77$ s. for the two vols.

Few branches of medical practice have witnessed $N$ more far-reaching developments in the last ten $\mathrm{N}$ years than the diagnosis and treatment of chest dis- $\omega$ orders. In none has the work of the physician and surgeon become more closely knit. This is par- 0 ticularly true of tuberculosis. In this disease the $\mathbb{D}$ range of the surgeon's interest has steadily increased $\stackrel{?}{?}$ pari passu with the greater reliance which he has 0 been able to place upon the intelligent use of modern

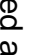

. 
drugs. If the co-operation, therefore, between physician and surgeon is indispensable to the patient's welfare, it has become equally indispensable to the preparation of a modern manual.

These two volumes comprise a collection of essays contributed by experts in their particular subject. It was not designed as a textbook; yet.it has become if not a textbook in name, certainly a work of reference in fact. A vast deal of ground has been covered with remarkably little overlap considering the number of individual contributors.

The first volume is concerned chiefly with the general aspects of the subject, such as epidemiology, the clinical and laboratory diagnosis of the disease, morbid anatomy, radiology, administration and rehabilitation. The minimal lesion with its special problems, fluorography, B.C.G. inoculation, psychology and tuberculosis in industry are all discussed. The second volume deals with the disease more precisely by systems and contains accounts of the surgical methods employed in treatment.

Considering the entire work it can be said that the main editorial difficulty of blending so large a number of separate contributions into a composite whole has been overcome. The result is a manual that is authoritative and complete, and one which will enhance the prestige of British medical practice.

\section{A SHORT PRACTICE OF SURGERY}

ByHamilton Bailey, F.R.C.S., F.A.C.S., F.I.C.S., F.R.S.E., and R. J. McNeILl Love, M.S., F.R.C.S., F.A.C.S., F.I.C.S. 9th Edition. Pp. viii + I,254, with 1,234 illustrations. London: H. K. Lewis \& Co., Ltd. 1952.

This excellent book is now presented in its ninth edition. The authors regret that owing to surgical advances they have had to enlarge it slightly. There are 206 extra pages and it is now as large as it can be if it is to be retained as a single volume work. It has been extensively revised and brought up to date. Portal hypertension has a section to itself and the peptic ulcer chapter has been enlarged. A more comprehensive account of carcinomata of the pharynx and larynx is welcomed. In the chapter on arterial disease there is a detailed account of modern methods of treatment but it is a pity that there has been no mention of arteriography in diagnosis. The illustrations, many of which have been changed, are excellent.

This book will justly continue to be one of the most popular books for medical students.

$$
\text { D.L.B.F. }
$$

\section{INTRODUCTION TO CLINICAL NEUROLOGY}

By Gordon Holmes, M.D., F.R.S. 2nd Edition. Pp. vii + r89, with 43 illustrations. Edinburgh: E. \& S. Livingstone. 1952. I2s. 6d.

This book, as the author writes in his preface, does not "describe or deal with injuries and diseases as such,' but it discusses 'the nature and the significance of the symptoms and abnormal signs which a patient with a nervous disorder may present or which may be revealed by clinical examina.'

It is a most excellent introduction to this aspect of the study of neurology. It is also more than an introduction as it is valuable and refreshing to the initiated. Whatever its title may suggest it is emphatically a book for practitioners as well as students.

To some extent it treats in cross section the facts which are listed, so to speak, longitudinally in text books of neurology, and in so doing it elucidates and compares the same or similar signs and symptoms in different diseases.

Here are some of its chapter headings: The Motor Systems, Muscle Tone and Co-ordination of Movement, Examination of the Motor System, Sensation, The Examination of Sensation, Reflexes, The Visual System, Speech and its Disorders, Agnosia and Apraxia, The Bladder and Rectum.

This somewhat random selection gives some idea of the plan. A book with this approach is refreshing and intriguing to read, especially one as thoughtful, compact and full of experience as this. There are all too few of its kind.

To the reviewer's knowledge there is certainly no book in the British literature which covers this book's territory in its particular way.

When one remembers the striking clarity of the author's bedside demonstrations it is surprising to find that the book contains a number of obscure sentences. Some are so because they are cumbersome and others because of inadequate proofreading. However, they do not seriously detract from an excellent book.

Every aspiring neurologist or medical consultant should read it, as should any student who aims at a competent grasp of the subject of neurology.

$$
\text { C.E. }
$$

\section{THE RHESUS FACTOR}

By G. Fulton Roberts, M.A., M.D. 3rd Edition.

Pp. vii +90 . London: William Heinemann. I952. 5s.

This booklet gives an excellent account of the Rhesus factor and its clinical implications. All the relevant information is clearly set out, and many case reports further illustrate the various points raised in the text. Naturally, the main appeal will be to those engaged in blood transfusion and obstetric practice, but the importance of the subject and clarity of presentation will make this booklet highly acceptable to all practitioners.

M.H.

\section{TUBERCULOSIS OF BONE AND JOINT}

By The Late G. R. Girdlestone and E. W. Somerville, M.B., F.R.C.S. 2nd Edition. Pp. xii +314 , with 182 illustrations. London: Geoffrey Cumberlege. 1952. 45s.

Published after the untimely death of Professor Girdlestone, this second edition will keep fresh the memory of a brilliant surgeon with the widest type 